Int. J. Electrochem. Sci., 16 (2021) Article ID: 210828

International Journal of

ELECTROCHEMICAL

SCIENCE

www.electrochemsci.org

\title{
Pt-Pd Bimetallic Nanocomposites Catalyst Formed on Graphene Surface: Preparation and high-performance for Methanol Electro-Oxidation
}

\author{
Zirong Li ${ }^{1, *}$, Tingting Cheng ${ }^{1}$, Lei Bai ${ }^{1}$ and Aiqin $\mathrm{Ye}^{2, *}$ \\ ${ }^{1}$ College of Chemistry and Materials Engineering, Anhui Science and Technology University, \\ Bengbu, Anhui, P.R. China, 233000 \\ ${ }^{2}$ School of Electrical and Electronic Engineering, Anhui Science and Technology University, Bengbu, \\ Anhui, P.R. China, 233000

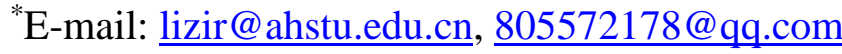

doi: $10.20964 / 2021.08 .10$

Received: 5 April 2021/ Accepted: 23 May 2021 / Published: 30 June 2021

Reduced graphene oxide (RGO) supported Pt-Pd bimetallic nanocomposites with "clean surface" were prepared by direct electrodeposition method on glassy carbon electrode (GCE). The obtained Pt-Pd decorated RGO nanohybrids were characterized by field emission scanning electronic microscope (FESEM), X-ray photoelectron spectroscopy (XPS), and electrochemical method. The results have showed that the synergistic effect of alloying with Pd in the Pt-Pd nanoclusters structure leads to much higher performance for methanol oxidation reaction (MOR) than pristine Pt nanoparticles. Moreover, with the support of RGO, the Pt-Pd nanocomposites show much better durability and high efficiency in MOR. This work can help us deeply understand the electrocatalytic mechanism for MOR and will benefit the selection of new catalysts with high efficiency and low cost.

Keywords: Pt-Pd nanoclusters, graphene, methanol electrooxidation

\section{$\underline{\text { FULL TEXT }}$}

(C) 2021 The Authors. Published by ESG (www.electrochemsci.org). This article is an open access article distributed under the terms and conditions of the Creative Commons Attribution license (http://creativecommons.org/licenses/by/4.0/). 